\title{
COMMUNICATION AND INTERACTION IN ART CLASSES
}

Maja Hrvanović1

Academy of Dramatic Arts, University of Tuzla

Received: 19.03.2014.

Accepted: 02.04.2014.
Original scientific paper

UDC: $371.3: 7.071$

\begin{abstract}
Numerous indicators affect communication and interaction in art classes. For every teacher, as pedagogue, his successful educational activity is very important as some indicators influence the two-way exchange of information in art classes. Teaching art is very specific way of teaching process, because it is mostly based on exchange of visual information of artistic type which represents a special form of communication. The specificity of artistic information, way of acting on the viewer and intense emotional charge in the process of communication should be used as visual stimulus. The richness of imagery, stimulation of reality, abstraction and other cognitive processes in art classes experientially and visually improve students' awareness and should be represented and diversified by origin and multiplied by quantity. The research paper aims to demonstrate the importance of connectivity between judgment of taste and ability to evaluate the quality of the work of art in art and non-art schools. Teaching and education in art classes is being realized precisely inside communicative relations and appropriate socio-emotional climate. In this research, visual communication in art classes is defined over the structure of the inventory that will examine the differences between abilities to evaluate the quality of artistic information and the judgment of taste.
\end{abstract}

Key words: Communication, interaction, visual information, judgment of taste, quality assessment, art classes, decoded content

\section{THE RESEARCH}

The intention of this research was to determine and numerically present findings which confirm the importance of connection between the judgment of taste and ability to estimate the quality of the work of art in non-art and art schools. Regression analysis on the sample of 407 respondents in art and non-art schools has shown indications that confirm the importance of interconnectedness of the judgment of taste and ability to estimate the quality of the work of art.

The starting point of the research was: specificity of artistic information, the way of acting on observer and the intense emotional charge in the process of communication that should be used as visual stimulus towards students.

The painting actually sends as much as the educa-

tion, skill and sensibility of the painter is; the observer invests equal investment mirroring his education in the painting, but there is also perception tied with his reception.(Huzjak, 2010, p.2.)

The aim of this research is theoretical and empirical examination of visual communications and interactions in the teaching of art and understanding its function in forming the ability to recognize and evaluate the works of art; i.e. the ability of active participation while transferring visual information, aesthetic and non-aesthetic content.

Evaluation variables are operationalized in two ways: quantitative- through liking and quality rates and quality- through criteria of rates of liking and quality.

${ }^{1}$ Correspodence to:

Maja Hrvanović, PhD, Academy of Dramatic Arts, University of Tuzla

E-mail: hrvanovi@yahoo.com 
The answer to the question, if all visual information in the teaching of art are completely adjusted to contemporary cultural frameworks and interests of students, is expected. The other group of questions is related to assessment of quality of communicative and interactive relations in the class of art, the assessment of quality of visual information in the classroom.

The questions in the instrument OKLIKO (Evaluation of quality of artistic achievement- EQAA), are related to students' ability to recognize the stylistic characteristic and artistic quality of the work of art. It is important to emphasize that the instruments are directed on examining the students, their opinion, their attitude and emotions, because we think that data obtained in that way will be more credible. On the other hand, in pedagogical way we are making a progress, because we allow students to be included in assessing the quality of the teaching process, as well as to participate in the process of analysis and innovation of the teaching process by giving suggestions and comments. The richness of the imagery, simulation of reality, abstraction and other cognitive processes in the teaching of art, visually enhance the students' awareness and should be represented and diversified in origin and multiplied by quantity. On the basis of structural organization of character code and hermeneutical study of meaning it is evident that visual language is trying to be the equivalent to another language. However, the translation of the painting into the word is not reversible, because it does not allow retranslating without significant loss. Visual signs inside their reciprocal relations build different connotative references, associations and emotional reactions, and influence on the way of decoding of the visual message and its content.

In terms of the principles of taste Kant sets up the following thesis:

- Judgment of taste is not based on concepts, otherwise it could be discussed over (decide on the basis of evidence)

- Judgment of taste is based on concepts, because, regardless to its diversity, it couldn't even be talked over (Asking for the necessary consent of others with this judgment).

Immanuel Kant, leaves inheritance to George Sim- mel, the unsolvable enigma in ,Kritik der Urtheilskraft", saying how judgment or judging power is individual and universal and subjective and objective at the same time. Working power, as a form of putting something special under general, Kant uses as connection between two other powers and maybe it will be the basis for a very particular part of philosophy, in the end that philosophy as a system can only have two parts" (Kant, 2004, p.11).

Painting as a character, specific type of character, is defined by means, by which it is expressed, the way the marked is connected to the significator. It is also defined by the relationship that exists between their referential, expressive and connotative functions, as well as the way it creates the complete meaning (Weltruski, 1980, pp. 137-150).

The interpretation of the essence of visual message, denotative an connotative aspect of the painting are not simple. Teacher in the course of two-way communication acts as a filter, presenter of decoding content, which means that understanding and acceptance of visual information firstly depends on his attitude, emotions, worldview and even formed taste. From Kant, we accept that our cognitive-perceptual apparatus produces the reality that we are familiar with.

\section{THE RESULTS OF THE RESEARCH}

On the sample of 407 respondents in art and nonart schools, using regression analysis, we received indications that confirm the importance of interconnectedness between judgment of taste and ability to evaluate the quality of the work of art. The result of the research confirms the fact that the intensity of experience of visual information of artistic type is related to the ability of its recognition and usage in art classes. All data were analyzed using statistical program SPSS 15 for Windows. It is about survey research where different variables are being intersected. These intersections have brought up useful insights and answered to the questions about the influence of artistic content of the viewer on the formation of the judgment of taste and precondition for evaluation of the quality of the artistic type information. 
Table 1. Assessment of liking in relation to quality assessment of the work of art

\begin{tabular}{lcccccc}
\hline \multicolumn{7}{c}{ Evaluation of the quality of the work of art } \\
Above \\
& $\begin{array}{c}\text { Below } \\
\text { average }\end{array}$ & Average & average & Total & $\chi^{2}$ & P \\
& 1 & & & & & \\
\hline Category & 4 & 1 & 0 & 5 & & \\
& $80,0 \%$ & $20,0 \%$ & $0 \%$ & $100 \%$ & & \\
Judgment & 25 & 90 & 8 & 123 & & \\
of & $20,03 \%$ & $73,2 \%$ & $6,5 \%$ & $100 \%$ & & \\
taste & 6 & 209 & 64 & 279 & & \\
& $2,2 \%$ & $74,9 \%$ & $22,9 \%$ & $100 \%$ & & \\
Total & 35 & 300 & 72 & 407 & & \\
\hline & 8,6 & 73,7 & 17,7 & $100 \%$ & 78,75 & 0,000 \\
\hline
\end{tabular}

Our variable Evaluation of artistic quality includes three categories: below average, average and above average (table 1.) According to chi-square test, that amounts 78,75, and statistical significance, we conclude that there are differences between category of evaluation of the artistic quality and category of liking. We can see that students who partially like all offered reproductions, precisely $75 \%$, have an average ability to evaluate the quality of the work of art. Works of art are completely liked by $23 \%$ of students, whose ability to evaluate the work of art is above average.

According to information theory by Echo, the artistic information is different from the information in the linguistic, verbal and cyber system, and is the most represented in the art classes. For one theory of information the heaviest information to transmit will be the one inclining to the wider area of recipient's sensibility, using wider channel, ready to let a larger number of elements, without filtration; this channel transmits a vast information but with risk to poor intelligibility. (Eco, 1965, p. 115)

Inside standard information system, information is proportional to the percentage of expected and its path from sender, through redundant channel, to recipient, ends the circle after the feedback from the sender. Redundancy or plethora of information is not functional and is considered a side effect of the ongoing communication. However, in artistic information redundancy can be information, as well. Its whose presence decreases monotony.

\section{CONCLUSION}

The value of artistic information is measured by quantity of "new" innovative, different content. The quality of artistic information depends greatly on viewer's experience. By intensity of experience, artistic visual information is being remembered, it is memorized by intensity of experience, not by historical, critical or some other category.

According to tabular overview Evaluation of the quality of the work of art category (Table 1.) we can see that $23 \%$ of total number of students have keen affinity towards works of art and their ability to evaluate the quality of the work of art is above the average. That tells us that specificity of artistic information, the way of action on the observer and intense emotional charge in the process of communication should be used as visual stimulus. The richness of imagery, imitation of reality, abstraction and other cognitive processes in teaching art promote students' awareness, both visually and experientially, and should be represented and diversified by origin and multiplied by quantity. Affinity towards specific type of art cannot be programmed, but built up gradually and guided slightly. 
Examination of quality of communicative and interactive relations in art classes we have confirmed that the quality of teaching process of art students measure by communication and interaction quality, which involves appreciation of personality and individual opinion, empathy, positive emotional climate, higher factor of enjoyment and emotional experience of artistic content, adjustment of visual information to interests and abilities of students, freedom to ask questions, two-way communication, presentation of several examples through visits to cultural institutions, improvement of creative needs through practical work and perception from closer surrounding. This paper gives the greatest practical contribution in the field of art education. Analyzing great numbers of data we get an insight to quality of visual information in the art classes, as well as students'abilities to perceive, understand and practically use that kind of information. Improvement of the level of visual communication enables more appropriate usage of visual media as well as more functional communication and interaction. Presented results will demonstrate the existing deviant relations of students towards the works of art of low value. It will contribute to the training of teachers to shape students' aesthetic attitudes as well as their need to exchange the critical thinking. Implementation of diverse visual content different by origin, type, and way of presentation will enrich the teaching of art and emphasize the importance of its being. Interests, critical attitudes and students' assessments pointed towards contemporary visual media should be guidelines to reshape teaching curriculum. Improvement of visual communication and interaction in the teaching process will build up the quality of visual information exchange, their form and utilitarianism. Artistic information since the modern art uses tendencies of "new" in its own favor; unpredictability in communication that shocks and surprises the viewer becomes the mean of attracting attention. It is necessary to enrich the art classes by different contents which will find its own way to the viewer, intensify the experience of artificial and attain the connection between intensity of experience of visual information of artistic type and ability of its memorization and usage in the process of teaching art, as well as interaction through artistic practice.

\section{REFERENCES}

Eco, U. (1965). Open Work. Sarajevo: Veselin Masleša. Huzjak, M. (2010). Transmutation, Intersemiotic Translation and Structural Correlation. Art education in school curriculum; University in Split, Faculty of philosophy and Croatian pedagogical literary society, department in Split. P.55-56, UDK 37.036 (497.5) (063), miroslav.huzjak@ufzg.hr (taken on 18th. February, 2011.)

Kant, I. (2004). The Critique of Judgment. Belgrade: 11. Almanac Novi Sad literary circle 1.

Weltruski, J. (1981). Plastic sign. Collection of articles from the theory of visual art, ed. Nenad Miščević and Milan Zinaić:

Rijeka: Publishing Center 